\title{
CHEMOSPHERE
}

\section{Biofiltration of trimethylamine-containing waste gas by entrapped mixed microbial cells}

\author{
Chang-Tang Chang ${ }^{\mathrm{a}, *}$, Bor-Yann Chen ${ }^{\mathrm{b}}$, I-Shing Shiu ${ }^{\mathrm{c}}$, Fu-Teng Jeng ${ }^{\mathrm{c}}$ \\ a Department of Environmental Engineering, National I-Lan University, I-Lan, Taiwan \\ ${ }^{\mathrm{b}}$ Department of Chemical Engineering, National I-Lan University, I-Lan, Taiwan \\ ${ }^{\mathrm{c}}$ Graduate Institute of Environmental Engineering, National Taiwan University, Taipei, Taiwan
}

Received 16 October 2002; received in revised form 25 March 2003; accepted 4 November 2003

\begin{abstract}
The study provides novel attempt to use an aerobic biofiltration system containing entrapped mixed microbial cells (EMMC) for removal of $\left(\mathrm{CH}_{3}\right)_{3} \mathrm{~N}$-dominant waste gases. In the study, heterotrophic microflora-immobilized cellulose was packed into an EMMC reactor to degrade $\left(\mathrm{CH}_{3}\right)_{3} \mathrm{~N}$. Effects of $\left(\mathrm{CH}_{3}\right)_{3} \mathrm{~N}$ inlet concentrations in continuous mode of operation at various flow rates are indicated. The result indicated that the $\left(\mathrm{CH}_{3}\right)_{3} \mathrm{~N}$ removal efficiency is higher than $90 \%$ at inlet loading below $27.2 \mathrm{mg} \mathrm{N} \mathrm{h}^{-1}$ and retention time $5.3 \mathrm{~min}$. In addition, the maximal mass loading to reach approximately $99 \%$ efficiency was $95.5 \mathrm{mg} \mathrm{N} \mathrm{h}^{-1}$ for trimethylamine treatment. This EMMC biofiltration system also showed higher tolerance to endure fluctuations in concentrations and flow rates and still maintained in stable performance for removal. Adaptability test in response to gradual shift up and down of inlet TMA loading indicated that lack of steady-state multiplicity and hysteresis guarantees the microbial communities more precisely adapted to continuous treatment for maintaining stability.
\end{abstract}

(c) 2003 Elsevier Ltd. All rights reserved.

Keywords: Biofiltration; Entrapped mixing microbial cell (EMMC); Trimethylamine (TMA); Maximum loading

\section{Introduction}

Biofiltration units are microbial ecosystems for the treatment of low-concentration and biodegradable waste gases. Trimethylamine (TMA) is potentially toxic and likely carcinogenic as a threat to public health, causing odor and visibility problems. Representative discharges of TMA are often from wastewater treatment, disposal waste landfill, livestock farming, and hog manure (Shieh and Keenan, 1986; Leson and Winer, 1991; Cao and Du, 1997). Characteristic concentrations of TMA emitted in such discharges ranged in 5-100 ppm (Shieh and Keenan, 1986; Hodge and Devinny, 1994). Therefore, levels of TMA must be reduced for emission under environ-

\footnotetext{
${ }^{*}$ Corresponding author. Fax: $+886-39359674$.

E-mail address: ctchang@ilantech.edu.tw (C.-T. Chang).
}

mental regulation not only to avoid safety and health hazards, but to eliminate environmental impacts as well (e.g. greenhouse effect, acid rain, and eutrophication; Furusawa et al., 1983; Sly et al., 1993). In particular, oxidation of TMA to $\mathrm{HNO}_{3}$ depletes dissolved oxygen of the receiving water body, and evolution of acid products corrodes the structure of the pipe (Wade et al., 1986; Tangji et al., 1989; Ziminski and Tang, 1994). According to Taiwan Environmental Protection Agency (TEPA), standard levels of ambient TMA for air quality regulation are $1.0 \mathrm{ppm}$.

In the past decade, attentions on treatment of TMA have been paid on the bioremediation perspective, as this method is more economically feasible and environmentally friendly compared to other conventional means (e.g., adsorption, absorption, and incineration). In addition, contaminants can be completely destructed at a lower cost and faster rate, and with no lingering 
liability. Although literature (Yang et al., 1994; Zita and Hermansson, 1994; Warren et al., 1997) mentioned that bioreactors packed with Nitrosomonas sp. have been only used to remove TMA in wastewater, application of a biofilter reactor for TMA treatment in waste gas is still remained open for discussion. Recently, attempts of cellimmobilization techniques have been applied to waste gas treatment (e.g. ammonia gas, Chung et al., 2001; Hartikainen et al., 2001); however, biochemical reaction characteristics for cell immobilization and treatment in TMA still need to be addressed to present the operation feasibility and system optimization. As Yang et al. (1997) mentioned, the inhibition of nitrification increased with TMA concentrations. Studies (Zilli and Lodi, 1993; Edwards and Nirmalakhandan, 1996; Chung et al., 2001) also indicated that the activated sludge, composing of Arthrobacter oxydans and Pseudomonas putida from swan wastewater treatment systems is very effective in removing $\mathrm{NH}_{3}$. Here, we also used the activated sludge for swan wastewater treatment as seeding cultures to conduct this treatability study for TMA treatment.

According to results of the entrapped mixing microbial cell (EMMC) bioreactor fed with TMA in various substrate concentrations, the removal efficiency and capacity for TMA as well as the property of compost odors were evaluated over time. As input parameters (i.e. shock loading, input concentrations of TMA) are of great significance to operation performance, the aim of the study is also to determine conditions of maximal mass loading and optimal operation conditions (e.g. pH, flow rate, retention time) for treatment. This novel attempt is to apply an EMMC approach to TMA-containing waste-gas treatment, resulting in high removal efficiency of more than $90 \%$.

\section{Materials and methods}

\subsection{Conditioning of immobilized cells}

The activated sludge (originally obtained from the swan wastewater treatment system in Hsinchu, Taiwan) was used as virgin (unconditioned) seeding cultures for EMMC. To maintain microbial activity and biological synchrony of EMMC cultures, acclimation of sludges was conditioned through total recycle of various fresh nutrient solutions, replenished each month and designed to acclimation in the specific pollutant. The component of inflow media contained $\mathrm{K}_{2} \mathrm{HPO}_{4} 1.5 \mathrm{~g} \mathrm{l}^{-1}, \mathrm{KH}_{2} \mathrm{PO}_{4}$ $1.8 \mathrm{gl}^{-1}, \mathrm{CaCl}_{2} 0.74 \mathrm{mgl}^{-1}$, glucose $2.5 \mathrm{gl}^{-1}$ (Chung et al., 2001). Nutrient-containing aqueous solutions were sprayed downward at a rate of $200 \mathrm{ml} \mathrm{min}^{-1}$ with a peristaltic pump (Masterflex, Model 7518) from the top of column for a week. $\mathrm{CO}_{2}$ evolution was continuously monitored to guarantee an ecologically stable activity of steady-state mixed consortia to be established. Cellulose triacetate was selected as a polymeric-material matrix for cells immobilization. The EMMC, including cellulose triacetate carrier and microbial cells, were obtained instantaneously via polymerization on 1-cm-diameter coimmobilized beads as Yang and See (1993) described. The prepared EMMC beads were packed into a fixed-bed column bioreactor for study. Harvested cells (precipitated through high-speed centrifuge, CEPA Laboratory Centrifuge type LE, $7500 \mathrm{~g}, 10 \mathrm{~min}$ ) were immobilized and entrapped onto the matrix. After the cell immobilization step, EMMC beads were placed into a 35.0-1 (20 $\mathrm{cm} \varphi \times 110 \mathrm{~cm} \mathrm{H})$ vertical column reactor with a working volume of $28.31(20 \mathrm{~cm} \varphi \times 90 \mathrm{~cm} \mathrm{H}, 80 \%$ of total column) at $25{ }^{\circ} \mathrm{C}$ for operation. Experimental schematic of the bioreactor set-up is shown in Fig. 1. Glass column was packed with $90 \mathrm{~cm}$ height EMMC, and a perforated sieve plate was fitted at the bottom of the column to ensure the uniform distribution and mass transfer of the inlet gas.

\subsection{Experimental equipment and procedure}

After conditioning, $\left(\mathrm{CH}_{3}\right)_{3} \mathrm{~N}$ containing waste-gases were pumped upward to increase mass transfer efficiency (Chung et al., 2001) through EMMC columns (retention times- $\mathrm{RT}$ ranged from 1.4 to $21.7 \mathrm{~min}$ ) for continuous treatment. Chung et al. (2001) mentioned that countercurrent flow in column provided the maximal mass transfer of gaseous pollutants. The new cells in the column were replenished each time for running every test. To ensure the removal efficiency, influent and effluent $\left(\mathrm{CH}_{3}\right)_{3} \mathrm{~N}$ concentrations were analyzed by on-line $\mathrm{GC} /$ PID. In the continuous flow experiment, the TMAcontaining waste gas was introduced into the reactor. Initially, the $\mathrm{pH}$ was controlled approximately at 4.0 10.0 to grasp the optimum $\mathrm{pH}$ for TMA removal. The

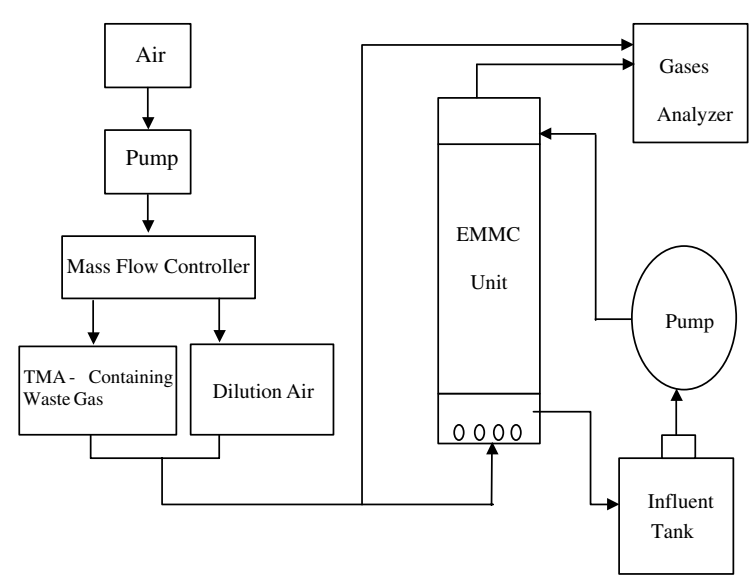

Fig. 1. The experimental set-up of the EMMC bioreactor. 
TMA concentrations (75-221 ppm in vol/vol) were supplied at various flow rates $\left(1.3-20.21 \mathrm{~min}^{-1}\right)$ at $\mathrm{pH}$ $7.0 \pm 0.5$. The removal efficiency and degraded product $\left(\mathrm{CO}_{2}\right)$ of the biosystem were determined as indicator measures. The more organic carbon utilized, the higher energy used and the more $\mathrm{CO}_{2}$ evolved during TMA removal. To evaluate the adaptability characteristics in response to shock-loading conditions (SLC), $75 \mathrm{ppm}$ TMA was introduced at 1.3 (pre-SLC) and $10.61 \mathrm{~min}^{-1}$ (post-SLC).

To reveal whether the treatment performance is due to pure sorption (i.e. absorption and adsorption) capability of packing matrices or biodegradation of EMMC, breakthrough curve experiments with blank filter were carried out at 75 ppm TMA $\left(1.3-20.21 \mathrm{~min}^{-1}\right.$; Fig. 2) in various flow rates.

\subsection{Analytical methods}

The TMA concentrations were measured continuously by GC-PID (HNU GC-311 with Porapak Q column, $2 \mathrm{~m} \times 0.32 \mathrm{~cm}$ ID). To guarantee reproducibility nature of results with statistical accuracy, the variation in inlet TMA concentration at steady-state within 3\% was maintained for QA/QC of data sampling. In addition, TMA outlet concentrations were determined by average of at least 10 sampled data points.

\subsection{Net maximum mass loading}

According to material balance upon the pollutant, Eq. (1) can be obtained as indicated in Zarook and Shaikh (1997). In addition, the rate of TMA degradation can be expressed in first order reaction kinetics (i.e. Eq. (1)), since the inlet concentration was low and substrate

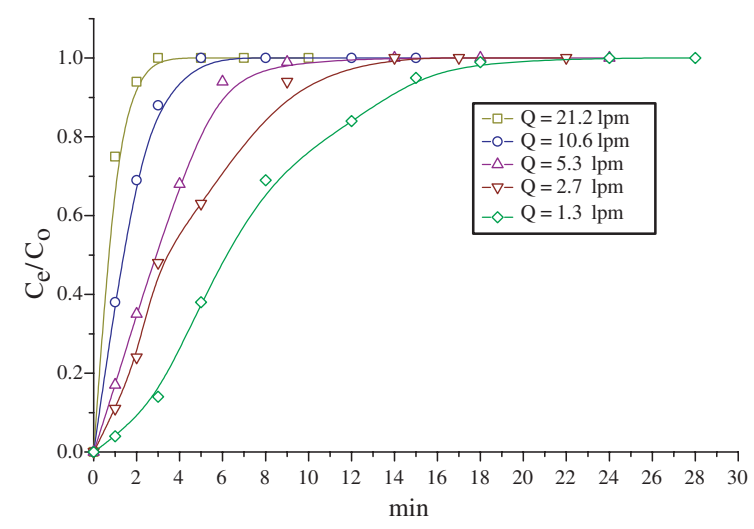

Fig. 2. Breakthrough curves of TMA removal with blank biofilter $(\mathrm{pH}=7.0) C_{e}$ and $C_{0}$ denote outlet concentration and inlet concentration, respectively. concentration was much less than half saturation constant, $K_{\mathrm{C}}$, in Monod's kinetic model, i.e.

$q_{\mathrm{p}}=\frac{q_{\max } C_{e}}{K_{\mathrm{C}}+C_{e}} \cong \frac{q_{\max }}{K_{\mathrm{C}}} C_{e}=k C_{e}$

$\frac{Q}{V}\left(C_{0}-C_{e}\right)-k C_{e}=\frac{\mathrm{d} C_{e}}{\mathrm{~d} t}$,

where $k, Q, C_{0}, C_{e}$ and $V$ represents decay rate (kinetic) constant, gaseous flow rate, inlet concentration, outlet concentration and working volume, respectively. The parameters $q_{\mathrm{p}}$ and $q_{\max }$ are the specific TMA degradation rate and maximal degradation rate, respectively.

At steady-state (i.e. $\frac{\mathrm{d} C_{e}}{\mathrm{~d} t}=0$ ), Eq. (1) can be written as Eq. (2).

$k=\frac{\mathrm{QC}_{0}-\mathrm{QC}_{e}}{\mathrm{VC}}$

When the decay rate constant approaches maximum, the net maximum mass loading (MML) can be predicted as an asymptote

$\mathrm{MML}=\left(\mathrm{QC}_{0}-\mathrm{QC}_{e}\right)_{\max }=\lim _{k \rightarrow \infty}\left(\mathrm{QC}_{0}-\mathrm{QC}_{e}\right)$.

The significance of the asymptote shows that net maximum mass loading is obtained when the reaction constant approaches zero, which indicates the inlet TMA to be eliminated completely.

\section{Results and discussion}

\subsection{Blank experiments}

As shown in breakthrough curves (Fig. 2), sorption saturation of blank filters was reached rapidly within 30 min (《effective operation time of EMMC ( $>5$ days)). The breakthrough time decreases with an increase in flow rate. It indicates that TMA sorption only occurs in short-term and much less significant to TMA biodegradation.

\subsection{Shock-loading effect}

As Fig. 3 indicated, the removal performance could be recovered to $90 \%$ removal efficiency in 2 days to respond the loading shift up from $3.3 \mathrm{mg} \mathrm{Nh}^{-1}(1.3$ $\left.1 \mathrm{~min}^{-1}\right)$ to $27.2 \mathrm{mg} \mathrm{Nh}^{-1}\left(10.61 \mathrm{~min}^{-1}\right)$ at fixed inlet TMA concentration ( $75 \mathrm{ppm}$ in vol/vol). However, poor removal efficiency $(<65 \%)$ was obtained as the loading changed to $51.9 \mathrm{mg} \mathrm{Nh}^{-1}$ (i.e. flow rate $20.21 \mathrm{~min}^{-1}$, concentration 75 ppm; Fig. 4). As the loading exceeds $27.2 \mathrm{mg} \mathrm{Nh}^{-1}$, induced degradation capacity cannot provide an efficient mechanism for removal due to relatively shorter retention time (RT; $2.7 \mathrm{~min}$, Fig. 4). Without sufficient RT, TMA cannot be effectively 


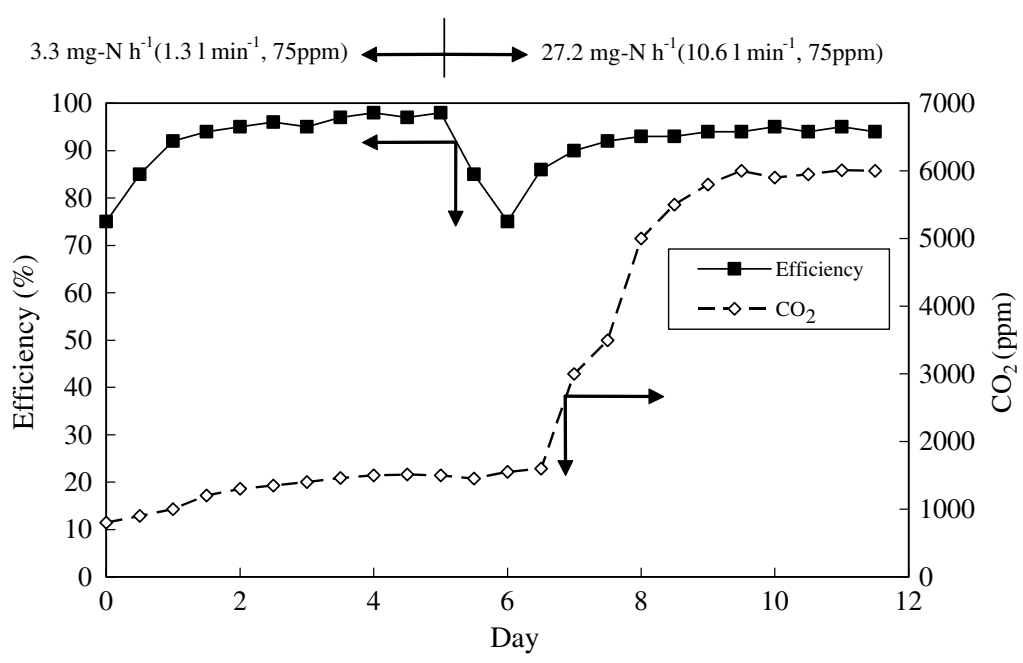

Fig. 3. The removal efficiency of TMA with EMMC biofiltration.

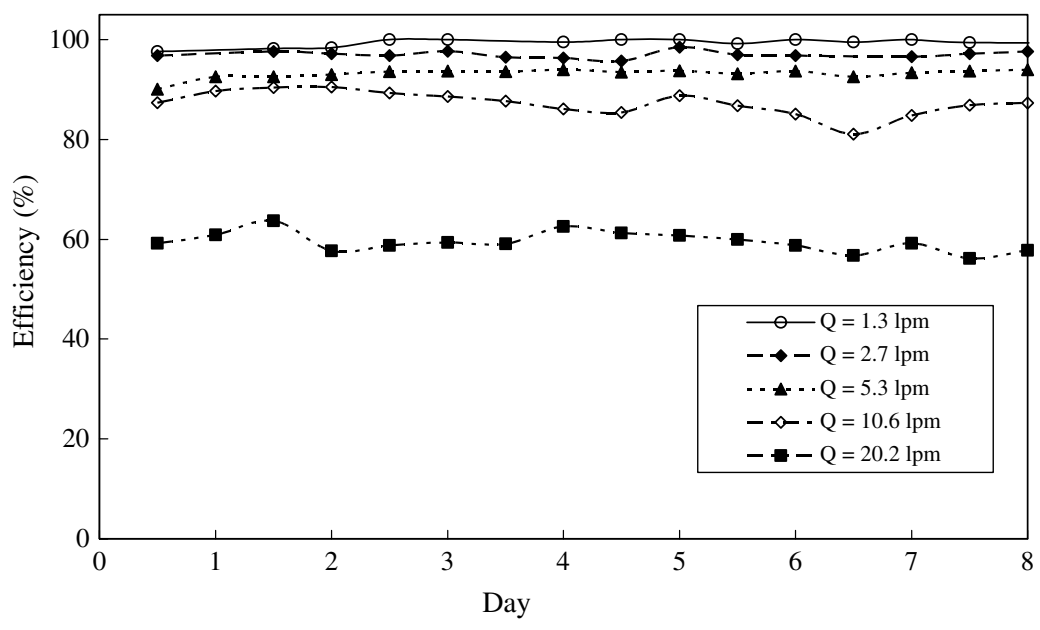

Fig. 4. The removal efficiency of TMA under different flow rate.

attached onto consortia existing on EMMC for degradation. In addition, there was a time delay for producing appropriate biodegradation activities in adapting to imposed environmental changes. This time-delay phenomenon is termed cell cycle or cell age related (Alberghina and Mariani, 1980). Once appropriate metabolic activity of microorganisms was induced, a new steady-state efficiency (94\%) could be achieved. With the incorporation of flow rate shift up, damped transient of TMA (from $\approx 97 \%$ to $85 \%$ ) was observed due to fast responses of biodegradation activity and a complete solubility of TMA. Adaptability tests in response to gradual shift up and down of inlet TMA loading indicated that lack of steady-state multiplicity and hysteresis guarantees the microbial communities more precisely adapted to continuous treatment for maintaining stability (Bailey and Ollis, 1997).

\section{3. $p H$ effects}

The steady-state $\mathrm{pHs}$ at various flow rates were approximately fixed in the range 7.0-8.0, indicating no significant acidification during the entire operation. The reasons for making such stable $\mathrm{pHs}$ are straightforward. Since TMA (acid ionization constant, $K_{b}=6.45 \times 10^{-5}$; AWMA, 2001) yields hydroxide ion $\left(\mathrm{OH}^{-}\right)$in aqueous solution, hydrogen ions formed by $\mathrm{CO}_{2}$ production, $\mathrm{CO}_{2}+\mathrm{H}_{2} \mathrm{O} \rightarrow \mathrm{H}_{2} \mathrm{CO}_{3}, \mathrm{H}_{2} \mathrm{CO}_{3} \rightarrow \mathrm{H}^{+}+\mathrm{HCO}_{3}^{-}$, can neu- 


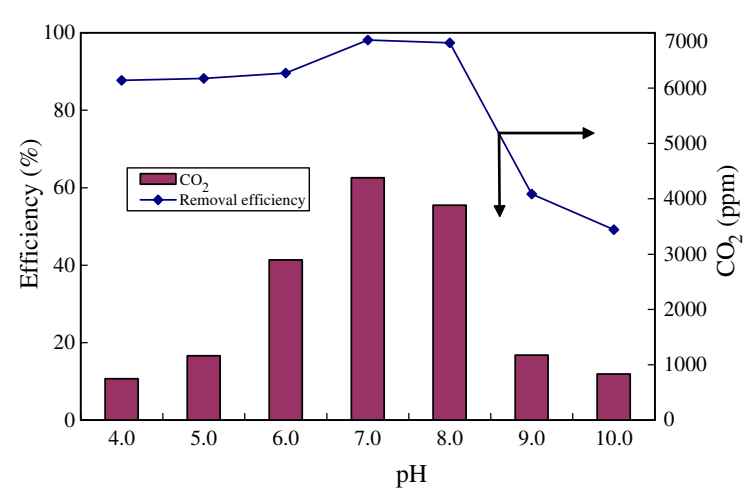

Fig. 5. $\mathrm{pH}$ effects on the removal efficiency of TMA at $10.6 \mathrm{lpm}$ and $75 \mathrm{ppm}$.

tralize hydroxide ions to maintain such stable $\mathrm{pHs}$ as shown in Fig. 5. Therefore, the system seems to possess natural $\mathrm{pH}$ buffers and keeps the $\mathrm{pH}$ from changing drastically.

The $\mathrm{CO}_{2}$ concentration was influenced intensely by $\mathrm{pH}$ of nutrient solution, and was lowered at $\mathrm{pH}<6.0$ and $>8.0$ (Fig. 5). In contrast, the efficiency was only changed slightly when $\mathrm{pH}$ was smaller than 6.0 , since the reaction $\mathrm{TMA} \rightarrow \cdots \rightarrow \mathrm{NH}_{4} \mathrm{OH}$ in aqueous solution caused neutralization. At low $\mathrm{pH}$, TMA biodegradation is inefficient due to neutralization predominated and low $\mathrm{CO}_{2}$ production. Therefore, optimal $\mathrm{pH}$ for TMA treatment should be ranged from 6.0 to 8.0. Moreover, it is suspected that a neutral $\mathrm{pH}$ is an optimal $\mathrm{pH}$ of maximal enzyme activities for TMA degradation. This point may exclude the predominance of certain microbes which are tolerant to alkaline or slightly acidic habitats (e.g. cyanobacteria) in EMMC.

\subsection{Flow rate effect}

Since the inlet loading of the system depends on inlet concentration and flow rate, effects of both factors must be investigated. Moreover, to determine design criteria for maintaining stable removal efficiency of EMMC, the effective loading capacity should be established. Here, we defined the loading leading to an efficiency more than $90 \%$ as a "critical loading state (CLS)". When input loading exceeds CLS, lower degradation efficiency is obviously resulted as the microbial consortium in EMMC cannot degrade TMA in such short retention time or high tolerant concentration. According to Fig. 4, the efficiency is still higher than $90 \%$ when the inlet loading is below $27.2 \mathrm{mg} \mathrm{Nh}^{-1}$ (i.e. inlet flow rate $<5.3$ $1 \mathrm{~min}^{-1}$, inlet concentration $75 \mathrm{ppm}$ ). In addition, $\mathrm{CO}_{2}$ concentrations increased with increased inlet loading.

\subsection{Inlet concentration effect}

To assess the loading effect on EMMC performance, inlet concentration effects were investigated. As the inlet concentration in practical operation is time-fluctuated, it is essential to demonstrate the adaptability of the system in response to dramatic change in inlet loading. A field operation was simulated by gradually increasing the inlet TMA concentration and then gradually returned to the normal operation concentration (75 ppm). This is sotermed stability test for "steady-state multiplicity and hysteresis" (Bailey and Ollis, 1997). Treatment experiments of shift up and down in concentrations of TMA (75-221 ppm) showed reversible hysteresis and did not display steady-state multiplicity in continuous operations (Fig. 6). Thus, this system has higher tolerance to

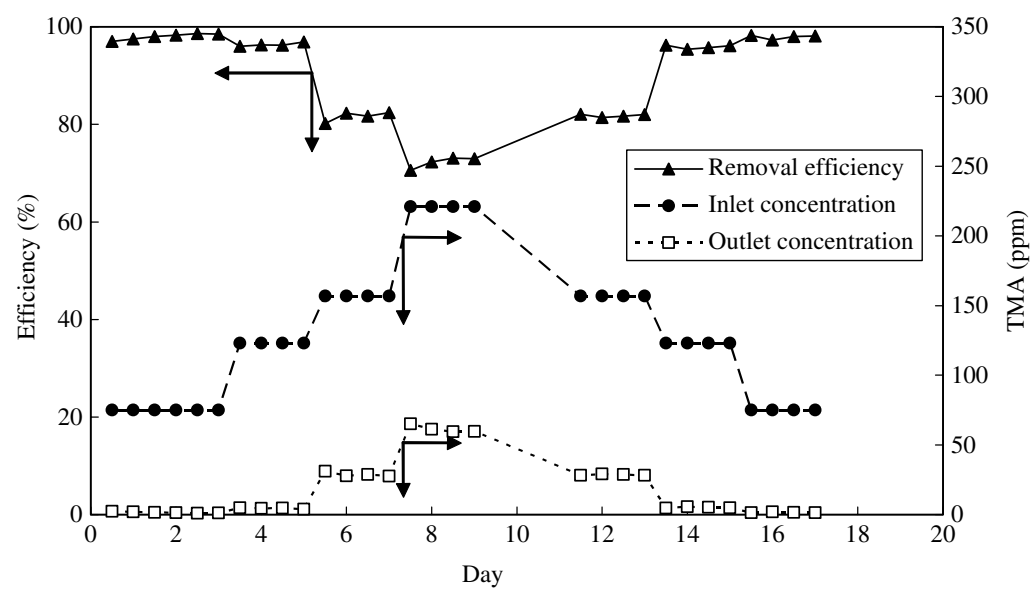

Fig. 6. The adaptability to dramatic change in inlet loading of TMA treatment at $2.7 \mathrm{lpm}$. Adaptation responses to gradual shift up and down of inlet TMA loading indicated that lack of steady-state multiplicity and hysteresis guarantees the microbial communities more precisely adapted to continuous treatment for maintaining stability. 
endure fluctuations in concentrations and still maintained in stable performance for removal.

CLS of TMA was $27.2 \mathrm{mg} \mathrm{Nh}^{-1}$ at inlet concentration smaller than $75 \mathrm{ppm}$ and flow rate $5.31 \mathrm{~min}^{-1}$. The predicted CLS of TMA based on inlet concentration effect was close to what was estimated from assessment of flow rate effect. According to Eq. (3), MML of TMA was obtained as $95.5 \mathrm{mg} \mathrm{N} \mathrm{h}^{-1}$. Therefore, the technically feasible range for TMA is approximately 27.2-95.5 $\mathrm{mg} \mathrm{Nh}^{-1}$ and much higher than the researched results (Chung et al., 2001) for $\mathrm{NH}_{3}$, only $0.02-0.24 \mathrm{mg} \mathrm{N} \mathrm{h}^{-1}$. It means that the EMMC has good performance since $\mathrm{NH}_{3}$ is easier to be treated than TMA.

\section{Conclusions}

This study provides a first attempt to apply an EMMC biofiltration approach for TMA-containing waste-gas treatment, resulting in high removal efficiency of more than $90 \%$. The maximal mass loading of EMMC to remove TMA is $95.5 \mathrm{mg} \mathrm{N} \mathrm{h}^{-1}$. In addition, the optimum $\mathrm{pH}$ of TMA is 7.0-8.0. Relatively shorter time ( $<2$ days) to reach steady-state conditions for TMA removal by the EMMC bioreactor was required. Acidification is negligible in TMA removal, since dissolved TMA is slightly alkali. Satisfactory removal efficiencies (90\% or higher) of TMA were reached at loading below $27.2 \mathrm{mg} \mathrm{N} \mathrm{h}^{-1}$. Further evidence in molecular level (e.g. bacterial identification, scanning electron microscopy) will be conducted for understanding species evolution in the microbial consortium.

\section{References}

Air and Waste Management Association, 2001. Air Pollution Engineering Manual. Van Nostrand Reinhold, New York.

Alberghina, L., Mariani, L., 1980. Analysis of cell cycle model for Escherichia coli. J. Math. Biol. 9 (3), 389-398.

Bailey, J.E., Ollis, D.F., 1997. Design and Analysis of Biological Reactors, second ed. Chemical Engineering Series, McGraw-Hill, New York. pp. 533-657.

Cao, N.J., Du, J.X., 1997. Production of fumaric acid by immobilized Rhizopus using rotary biofilm contactor. Appl. Biochem. Biotechnol. 63 (3), 387-394.

Chung, Y.C., Huang, C.P., Liu, C.H., Bai, H.L., 2001. Biotreatment of hydrogen sulfide- and ammonia-containing waste gases by fluidized bed bioreactor. J. Air Waste Manage. Assoc. 51 (9), 163-172.
Edwards, F.G., Nirmalakhandan, N., 1996. Biological treatment of airstreams contaminated with VOCs: an overview. Water Sci. Technol. 34 (3), 565-571.

Furusawa, N., Togashi, I., Hirai, M., Shoda, M., Kubota, H., 1983. Removal of hydrogen sulfide by a biofilter with fibrous peat. J. Ferment. Technol. 62 (3), 589-601.

Hartikainen, T., Ruuskanen, J., Martikainen, P., 2001. Carbon disulfide and hydrogen sulfide removal with a peat biofilter. J. Air Waste Manage. Assoc. 51 (9), 387-392.

Hodge, D.S., Devinny, J.S., 1994. Biofilter treatment of ethanol vapors. Environ. Prog. 13 (5), 167-173.

Leson, G., Winer, A.M., 1991. Biofiltration - an innovative air pollution control technology for VOC emission. J. Air Waste Manage. Assoc. 41 (11), 1045-1054.

Shieh, W.K., Keenan, D.J., 1986. Fluidized bed biofilm reactor for wastewater treatment. Biochem. Eng. 33 (5), 132-168.

Sly, L.I., Bryant, L.J., Cox, J.M., Anderson, J.M., 1993. Development of a biofilter for the removal of methane from goal mine ventilation atmospheres. Appl. Microbiol. Biotechnol. 39 (3), 400-404.

Tangji, Y., Kanagawa, T., Mikami, E., 1989. Removal of dimethyl sulfide, methyl mercaptan, and hydrogen sulfide by immobilized Thiobacillus thiopares TK-M. J. Ferment. Bioeng. 67 (2), 280-293.

Wade, A., Shoda, M., Kubota, H., Kobayashi, T., Yoko, K.F., Kuraishi, H., 1986. Characteristics of $\mathrm{H}_{2} \mathrm{~S}$ oxidizing bacteria inhabiting a peat biofilter. J. Ferment. Bioeng. 64 (1), 161-176.

Warren, J.S., Raymond, C.L., Fellow, A., 1997. Biofiltration fundamentals, design and operations principles, and applications. J. Environ. Eng. 32 (3), 538-546.

Yang, P.Y., Ma, T., See, T.S., Nitisoravut, N., 1994. Applying entrapped mixed microbial cell techniques for biological wastewater treatment. Water Sci. Technol. 29 (2), 487-495.

Yang, P.Y., See, T.S., 1993. Entrapment of mixed microbial cells for water and wastewater treatment. Water Sci. Technol. 28 (1), 165-170.

Yang, P.Y., Zhang, Z.Q., Jeong, B.G., 1997. Simultaneous removal of carbon and nitrogen using an entrapped-mixedmicrobial-cell process. Water Res. 31 (12), 2617-2625.

Zarook, S.M., Shaikh, A.A., 1997. Analysis and comparison of biofilter models. Chem. Eng. J. 65 (1), 55-61.

Zilli, M.A., Lodi, A., 1993. Phenol removal from waste gases with a biological filter by Pseudomonas putida. Biotechnol. Bioeng. 41 (3), 693-699.

Ziminski, R.W., Tang Y., 1994. Control of hazardous air pollutants using a commercial biofilter. In: Proceedings of the 87th Annual Meeting and Exhibition, Air and Waste Management Association, Cincinnati, Ohio.

Zita, A., Hermansson, M., 1994. Effects of ionic strength bacterial adhesion and stability of floc in a wastewater actived sludge system. Appl. Environ. Microbiol. 60 (12), 3041-3048. 